\title{
O impacto de mostras científicas no processo de alfabetização científica de crianças da educação infantil
}

\author{
The impact of scientific shows on the scientific literacy process of \\ children in childhood education

\section{El impacto de las exposiciones científicas en el proceso de alfabetización científica de los niños en la educación infantil}

\author{
Marco Aurélio Alvarenga Monteiro, (marco.monteiro@unesp.br) \\ Universidade Estadual Paulista "Julio de Mesquita Filho" - Unesp.
}

Rodolfo Meissner Rolando, (Rodolfo.meissner@unesp.br) Universidade Estadual Paulista "Julio de Mesquita Filho" - Unesp.

Danielle Silva de Novais Teixeira, (daniellenovais@gmail.com) Universidade Estadual Paulista “Julio de Mesquita Filho" - Unesp.

Resumo: A sociedade atual, parametrizada pelo desenvolvimento científico e tecnológico, oferece uma série de facilidades e melhorias para a vida do cidadão nas diferentes áreas da atuação humana, como nas comunicações, na saúde, nos transportes e até mesmo no lazer. Se essa realidade é bem-vinda pela comodidade e bem-estar que oportuniza, concomitantemente, gera demandas significativas em torno da escola e dos processos que formam os indivíduos para o exercício consciente, crítico e atuante da cidadania. Assim sendo, a educação científica se faz cada vez mais necessária ao cidadão e, por isso, deve iniciar cada vez mais cedo. O termo Alfabetização Científica foi cunhado no intuito de chamar a atenção para a necessidade que se tem de oferecer meios para que as pessoas sejam capazes de ler o mundo à sua volta a partir da linguagem científica, apropriando-se dela para participar das discussões que buscam maneiras de aperfeiçoá-lo. Neste trabalho apresentamos uma discussão sobre os resultados de uma pesquisa que estudou o impacto de mostras científicas para o processo de alfabetização científica de alunos da Educação Infantil. Para tanto, entrevistamos três turmas de alunos da Educação Infantil, cuja faixa etária variava entre 4 e 5 anos, totalizando 47 alunos, antes e após apresentarmos uma mostra de experimentos de demonstração de fenômenos físicos. A entrevista foi coletiva, envolvendo alunos de cada turma numa roda de conversa sobre os temas científicos abordados na mostra. Os resultados apontaram para a existência de uma ampliação significativa do repertório cultural dos alunos, o que pode auxiliar a formalização da aprendizagem em etapas posteriores de ensino.

Palavras-chave: Alfabetização Científica; mostra científica, linguagem e cognição. 
Abstract: Today's society, parameterized by scientific and technological development, offers a series of facilities and improvements for the life of the citizen in different areas of human activity such as communications, health, transport and even leisure. If this reality is welcomed due to the convenience and well-being that it provides, at the same time, it generates significant demands around the school and the processes that form individuals for the conscious, critical and active exercise of citizenship. Therefore, scientific education is increasingly necessary for the citizen and, therefore, it must start earlier and earlier. The term Scientific Literacy was coined in order to draw attention to the need to offer means for people to be able to read the world around them from the scientific language, appropriating it to participate in the discussions they seek ways to improve it. In this work, we present a discussion about the results of a research that studied the impact of scientific exhibitions for the process of scientific literacy of students of Early Childhood Education. To this end, we interviewed three groups of Early Childhood Education students, whose age range varied between 4 and 5 years, totaling 47 students, before and after presenting a sample of experiments demonstrating physical phenomena. The interview was collective, involving students from each class in a conversation round about the scientific topics covered in the exhibition. The results pointed to the existence of a significant expansion of the students' cultural repertoire that can help formalize learning in later stages of teaching.

Keywords: Scientific Literacy; scientific shows, language and cognition

Resumen: La sociedad actual, parametrizada por el desarrollo científico y tecnológico, ofrece una serie de facilidades y mejoras para la vida de los ciudadanos en diferentes ámbitos de la actividad humana, como las comunicaciones, la salud, el transporte e incluso el ocio. Si esta realidad es acogida por la comodidad y el bienestar que brinda, al mismo tiempo genera importantes demandas en torno a la escuela y los procesos que forman los individuos para el ejercicio consciente, crítico y activo de la ciudadanía. Por tanto, la educación científica es cada vez más necesaria para el ciudadano y, por tanto, debe empezar cada vez más temprano. El término Alfabetización Científica se acuñó con el fin de llamar la atención sobre la necesidad de ofrecer medios para que las personas puedan leer el mundo que les rodea desde el lenguaje científico, apropiándose de él para participar en las discusiones que buscan formas de mejorarlo. En este artículo presentamos una discusión sobre los resultados de una investigación que estudió el impacto de muestras científicas para el proceso de alfabetización científica de los niños en Educación Infantil. Para ello, entrevistamos a tres clases de alumnos de Educación Infantil, cuyo rango de edad osciló entre 4 y 5 años, totalizando 47 alumnos, antes y después de presentar una muestra de experimentos demostrativos de fenómenos físicos. La entrevista fue colectiva, involucrando a los estudiantes de cada clase en un círculo de conversación sobre los temas científicos tratados en la exposición. Los resultados apuntan a la existencia de una expansión significativa del repertorio cultural de los estudiantes, lo que puede ayudar a la formalización del aprendizaje en etapas posteriores de la enseñanza.

Palabras-clave: Alfabetización científica; exhibición científica, lenguaje y cognición 


\section{INTRODUÇÃO}

O fenômeno da globalização da economia, marcado pela intensificação da concorrência econômica, tem ampliado as exigências por inovação e desenvolvimento científico e tecnológico. Isso tem gerado demandas cada vez maiores em relação à formação do cidadão (SACRISTÁN, 2003; GUERRA, 2004).

Cada vez mais parametrizada pela Ciência, a sociedade que construímos exige dos cidadãos não apenas o conhecimento de conceitos científicos, mas também a capacidade de compreender a natureza da Ciência, do fazer científico, da maneira em que evidências experimentais se transformam em verdades científicas e como todo esse processo impacta nossas vidas e o meio ambiente (MONTEIRO, 2006).

Nessa direção, Chassot (2003) afirma que até a década de 1990, a preocupação em torno do Ensino de Ciências limitava-se à compreensão do conteúdo científico, exigindo-se dos estudantes habilidades e competências meramente cognitivas. Contudo, essa noção se modificou à medida que se intensificou o processo de globalização.

Como elucida Freire (1979), o processo educativo, como fenômeno social e histórico, está, inevitavelmente, ligado ao mundo globalizado sem, contudo, deixar-se manipular por ele e, nesse caso, a formação do cidadão crítico, atuante e responsável socialmente é fundamental. É possível dizer, dessa forma, que a formação do estudante para a compreensão crítica da Ciência e seus impactos sobre o mundo social torna-se tarefa iniludível da escola.

Assim, o objetivo deste artigo é discutir os impactos que uma mostra científica pode trazer para a alfabetização científica de estudantes da Educação infantil. A relevância dessa investigação consiste em problematizar a interpretação já cristalizada no senso comum de que o contato de crianças dessa faixa etária com a Ciência não seria pedagogicamente pertinente (e até viável) nesta etapa escolar. 
Para produzir os dados da pesquisa aqui relatada, participaram do estudo alunos da Educação Infantil de três escolas diferentes de um município do interior do Estado de São Paulo - Região do Vale do Paraíba. A mostra de ciências que apresentamos a ele contou com vinte e cinco experimentos demonstrativos contemplando temas como ótica, termodinâmica, ondulatória (som), eletricidade, magnetismo e eletromagnetismo. Os estudantes foram entrevistados antes e após a vivência da mostra científica.

Na seção de discussão de dados, nos apoiaremos nas orientações da BNNC sobre Educação Infantil, no conceito de alfabetização científica e em pressupostos vygotskyanos sobre linguagem, mediação e ZDP, o que nos auxiliará na compreensão mais apurada dos dados produzidos neste trabalho.

Para fins de organização, este artigo de divide em: fundamentação teórica, em que apresentamos o referencial teórico que sustenta a discussão aqui apresentada; metodologia, em que descrevemos, detalhadamente, os procedimentos de produção e análise de dados a partir do contato das crianças da Educação infantil com a mostra científica e, por fim, a discussão dos dados produzidos com o intuito de refletir sobre os impactos da mostra aqui descrita para a alfabetização científica dos sujeitos de pesquisa.

\section{INTRODUÇÃO TEÓRICA}

Nesta seção, primeiramente, discutiremos os direitos de aprendizagem e as esferas de atuação propostas para a Educação Infantil, conforme orientações da BNCC, coadunando o documento com a noção de alfabetização científica. Na sequência, apresentaremos alguns pressupostos vygotskyanos, considerados centrais para a compreensão dos dados produzidos.

\subsection{BNCC, Educação Infantil e os direitos de aprendizagem da criança}

$\mathrm{Na}$ sociedade hodierna, multiplicam-se e diversificam-se os objetivos educacionais que se fazem necessários ao processo de formação do cidadão, que, além de compreender conceitos científicos, deve ser capaz de compreender a sociedade em que vive, agindo criticamente sobre ela. 
Por isso, formou-se uma espécie de consenso entre pesquisadores e educadores de que devemos iniciar esse processo educativo precocemente, de modo a se iniciar um processo de Alfabetização Científica, de forma escolarizada, já nas séries iniciais do Ensino Fundamental (BRITO e FIREMAN, 2014; SASSERON e CARVALHO, 2011; BRANDI e GURGEL, 2002; DELIZOICOV e LORENZETTI, 2001). Entretanto, há aqueles que pregam que essa ação educacional deve ter início já na Educação Infantil (BORGES, RAMOS e AMORIM, 2014; ALMEIDA E TERÁN, 2013; BERSCH, et.al. 2013).

Mas o que é esse processo de Alfabetização Científica? É possível compatibilizar o processo de Alfabetização Científica e as especificidades da Educação Infantil? Para Delizoicov e Lorezetti (2008) a Alfabetização científica é um processo no qual um indivíduo desenvolve a capacidade de ler e compreender assuntos sobre a Ciência e em condições formar e expressar suas opiniões acerca deles. ]Em direção semelhante, Chassot (2014) afirma que a Alfabetização Científica estaria relacionada a saberes necessários para que o indivíduo seja capaz de fazer uma leitura do mundo a partir da Ciência e, por meio desse movimento, ser capaz de agir sobre ele, transformando-o para melhor.

Aguilar (1999) e de Puigcerver e Sans (2002), por sua vez, evidenciam que o cidadão alfabetizado cientificamente deve, além de conhecer a natureza da Ciência e o trabalho dos cientistas, também apropriar-se da linguagem cientifica de forma lógica e racional, compreender os procedimentos relativos ao estudo de um fenômeno científico e aplicar os conhecimentos científicos para resolver problemas do dia a dia.

Essas discussões vão ao encontro dos objetivos estabelecidos pela Base Nacional Comum Curricular - BNCC (BRASIL, 2017). Vale ressaltar que a BNCC não é uma proposta curricular, mas é um documento em que se definem os saberes conceituais, procedimentais e atitudinais que os alunos deverão portar ao concluírem a Educação Básica que se inicia na Educação Infantil e termina no Ensino Médio.

Tal documento se organiza com base em dez competências gerais a serem desenvolvidas pelos estudantes ao longo de toda a Educação Básica: Três contemplam as dimensões cognitivas, três dizem respeito às capacidades comunicativas e quatro referem-se ao desenvolvimento das competências socioemocionais. 
A BNCC - (BRASIL, 2017, p. 23) determina seis direitos de aprendizagem e desenvolvimento a serem garantidos à criança nessa etapa da Educação Básica:

- Conviver com outras crianças e adultos, em pequenos e grandes grupos, utilizando diferentes linguagens, ampliando o conhecimento de si e do outro, o respeito em relação à cultura e às diferenças entre as pessoas.

- Brincar cotidianamente de diversas formas, em diferentes espaços e tempos, com diferentes parceiros (crianças e adultos), ampliando e diversificando seu acesso a produções culturais, seus conhecimentos, sua imaginação, sua criatividade, suas experiências emocionais, corporais, sensoriais, expressivas, cognitivas, sociais e relacionais.

- Participar ativamente, com adultos e outras crianças, tanto do planejamento da gestão da escola e das atividades propostas pelo educador quanto da realização das atividades da vida cotidiana, tais como a escolha das brincadeiras, dos materiais e dos ambientes, desenvolvendo diferentes linguagens e elaborando conhecimentos, decidindo e se posicionando.

- Explorar movimentos, gestos, sons, formas, texturas, cores, palavras, emoções, transformações, relacionamentos, histórias, objetos, elementos da natureza, na escola e fora dela, ampliando seus saberes sobre a cultura, em suas diversas modalidades: as artes, a escrita, a ciência e a tecnologia.

- Expressar, como sujeito dialógico, criativo e sensível, suas necessidades, emoções, sentimentos, dúvidas, hipóteses, descobertas, opiniões, questionamentos, por meio de diferentes linguagens.

- Conhecer-se e construir sua identidade pessoal, social e cultural, constituindo uma imagem positiva de si e de seus grupos de pertencimento, nas diversas experiências de cuidados, interações, brincadeiras e linguagens vivenciadas na instituição escolar e em seu contexto familiar e comunitário (BRASIL, 2016).

Todos esses direitos de aprendizagem podem ser contemplados em uma atividade de alfabetização científica, dependendo da maneira como elas forem desenvolvidas em sala de aula, já que podem possibilitar que a criança:

- conviva com outras crianças, bem como outros adultos, se inteirando e discutindo temas da cultura científica;

- brinque, já que a atividade de alfabetização científica pode ser planejada de modo a ter um caráter lúdico;

- participe de forma ativa e autônoma já que as atividades de investigação e experimentação permitem a livre manipulação e exploração 
do universo de atuação da criança na busca por satisfazerem suas curiosidades;

- $\quad$ explorarem, diferentes situações de modo a buscarem estabelecer relações de causa e efeito sobre fenômenos que ocorrem à sua volta;

- expressar-se, livremente, pois que podem construir hipóteses, explicações e argumentos sobre fatos estudados, sem falar das reações emocionais desencadeadas pelo encanto e pela surpresa.

- Conheça-se, já que o conhecimento científico não apenas revelará saberes sobre o dia a dia da criança como também sobre seu corpo e sobre as coisas ao seu redor.

A BNCC também refere-se à necessidade de oportunizar cinco campos de experiência às crianças permitindo que elas vivenciem situações importantes para seu crescimento :

-O eu, o outros e o nós;

- Corpo, gestos e movimentos;

- Traços, sons, cores e formas;

- Oralidade e escrita;

-Espaços, tempos, quantidades, relações e transformações (BRASIL, 2017, p. 23).

Com relação ao primeiro campo de experiência: o eu, os outros e o nós, espera-se que os alunos possam vivenciar situações que facilitem a construção de sua identidade, do senso de subjetividade, a partir das interações que mantém com o professor e seus amigos de classe, compreendendo os princípios de respeito aos valores, à cultura, à diversidade.

No segundo campo de experiência: corpo, gestos e movimentos, espera-se que os estudantes possam a partir de certas situações conhecer o próprio corpo, o espaço à sua volta, as diferentes formas de movimento e de expressão corporal. Nesse caso destacamse atividades como o teatro, a dança, a música e diferentes manifestações culturais. 
No terceiro campo de experiências: traços, sons cores e formas, espera-se que os alunos vivenciem situações para a ampliação de sua sensibilidade estética, numa perspectiva crítica, exigindo bases de conhecimento artístico, cultural e científico. Em um espectro de possibilidades, pode-se propor situações que permitam a vivencia de diferentes ritmos, repertórios musicais, sons, desenhos, representações, pinturas, esculturas, etc.

No quarto campo de experiências: escuta, fala, pensamento e imaginação, esperase que os alunos vivenciem situações que ampliem sua capacidade comunicativa, de expressão de ideias, sentimentos. Daí a importância da leitura, da escrita, da fala.

Por fim, no quinto e último campo de experiências: espaço, tempo, relações e transformações, espera-se que os alunos possam vivenciar as situações de tempo e espaço, quantificando-as para estabelecer comparações e observar transformações e mudanças. A intenção é que o desenvolvimento dessa potencialidade permita ao indivíduo ser capaz de estabelecer relações de causalidade, construir explicações, para, dessa forma, planejar, prever.

As atividades de alfabetização científica por meio da realização de mostras científicas podem permitir essas vivências nos cinco campos de experiências propostas. Assim, é possível realizar atividades de alfabetização científica na Educação Infantil, não deixando de atender a nenhum requisito curricular previsto na BNCC. Feitas essas primeiras considerações, passaremos, a seguir, a discutir a perspectiva vygotskyana sobre ensino-aprendizagem.

\subsection{Alfabetização científica na Educação Infantil à luz do pensamento vygotskyano}

Na Teoria Sociocultural de Vygotsky, o desenvolvimento cognitivo do indivíduo ocorre seguido pela evolução cultural, considerando que esse processo se estabelece, primeiramente, num estágio determinado por um contexto social, ou seja, interpsicológico, e, depois, em outro estágio de caráter completamente individual, ou seja, intrapsicológico (VYGOTSKY, 1991).

Ou seja, o aprendiz interage com a cultura nova que vai aprender por meio das múltiplas e diversas interações sociais que mantém com outros indivíduos utilizando, 
para isso, da linguagem. É importante notar que, por linguagem, não se deve compreender apenas a fala, a palavra emitida a partir do som, mas a possibilidade humana, social e histórica, de atribuir sentido à comunicação por meio de um movimento constitutivamente dialógico do sujeito (BAKHTIN, [1979] 2011).

Dessa forma, recorremos a essa noção de linguagem para destacar que um experimento construído por um membro da comunidade científica, com base em justificativas e argumentos, bem como exposição de ideias, acerca de um fenômeno natural é uma forma viva de linguagem, ou seja, um meio de se estabelecer o processo de interação social com o outro na comunicação (Vygotsky, 1991).

Nesse sentido, para o epistemólogo russo, a linguagem é uma construção humana que ocorre em função da necessidade do ser em se socializar. Assim, neste contexto próprio do processo comunicativo, que ocorre entre duas ou mais pessoas, os seres são estimulados pelo meio sociocultural em que vivem, propiciando o desenvolvimento de ideias, pensamentos, lógica, ou seja, as ferramentas por meio das quais podemos decifrar o mundo (VYGOTSKI, 1988)

Tendo em vista essas explicações iniciais sobre a perspectiva sócio-histórica, vemos no conceito vygotskyano ([1934] 2007) de ZDP o respaldo teórico para nossa sugestão em coadunar os direitos de aprendizagem e os campos de experiência da Educação Infantil com a Alfabetização científica. Isso porque, na ZDP engendrada pelo movimento de alfabetização científica, pode-se impulsionar as crianças ao desenvolvimento e à descoberta do "novo". Na mesma direção, Oliveira e Travain (2019) argumentam que a organização da experiência escolar, embasada em Vygotsky, pode favorecer a compreensão crítica sobre questões de cunho tecnológico-científico. Antes de discutirmos esses aspectos, faremos, neste momento, breves e necessárias considerações sobre linguagem/mediação.

Transgredindo a ideia de linguagem como mero meio de comunicação e elevandoa a um papel de maior relevância no seio das tradições do pensamento marxista, Vygotsky desvela a natureza mediadora por excelência da linguagem, pois, por meio dela, os homens se organizam, apropriam-se das experiências individuais e coletivas, constituem-se como seres históricos e sociais e participam da cultura na qual estão 
inseridos, da qual a Ciência, sem dúvida, representa uma de suas mais bem acabadas manifestações.

Dessa forma, para compreender melhor a ideia de mediação entre o homem e o mundo por meio da linguagem, faz-se necessário explicar melhor as ponderações vygotskyanas a respeito de sentido e significado. Para o autor ([1934] 2008), o significado é uma produção social, convencional e possui natureza relativamente estável. É por meio do significado que os sujeitos vão se apropriando de produções socioculturais acumuladas pela humanidade. O sentido, por sua vez, é marcado pelo dinamismo e instabilidade, estando restrito a um dado espaço-tempo. Procurando clarificar essa discussão, Liberali (2011, p.46) afirma que "o sentido marca a individualidade nas consciências, que seria justamente a forma como significados historicamente marcados são internalizados e externalizados por cada um”, o que contribuirá, mais à frente, para a compreensão dos dados analisados neste artigo.

Partindo dessa visão, Vygotsky vê na atividade mediada a possibilidade de uma mudança radical no curso do desenvolvimento humano. Por meio das interações e inserção na vida social, o homem supera os processos elementares de ordem predominantemente biológica e alcança as chamadas funções psicológicas superiores, cuja gênese é sócio-histórica.

Nesse sentido, é possível afirmar que, participando de vivências que favoreçam o processo de alfabetização científica, as crianças, na Educação Infantil, podem ter o seu desenvolvimento potencializado, uma vez que o contato com a ciência e seus artefatos culturais, necessariamente, retira a criança de suas experiências cotidianas, lançando-as ao campo simbólico, mediado e social do campo científico, o que, de forma lúdica e criativa, poderá favorecer o seu desenvolvimento. Além disso, a criança será capaz de expressar, no contato com a alfabetização científica, novos sentidos sobre suas vivências e como compartilhar novos significados, bem como dar maior vazão aos aspectos lúdicos típicos desta fase, como explica Oliveira (2020).

Aproximando a ideia de mediação de contextos escolares, é possível afirmar, tomando como base os apontamentos de Ninin (2013), que, no processo de mediação, está implicada a ideia de agir com o outro no intuito de gerar conflitos que sejam resolvidos por meio de avanços nas formas de pensar e de agir dos sujeitos. Na 
Educação Infantil, a mediação pode ocorrer, por exemplo, quando o outro é provocado, por meio de perguntas e questionamentos suscitados por experimentos científicos, a (re)pensar seu conhecimento espontâneo e, nesse movimento, ampliar seu repertório, transformando-se.

Neste ponto, cabe associar o processo de mediação à possibilidade de criação de ZDP. Para Vygotsky ([1934] 2007), a Zona de Desenvolvimento Proximal representa a distância entra aquilo que a criança já consegue realizar sozinha - desenvolvimento real - e aquilo que ela consegue fazer com a ajuda de um adulto ou alguém mais experiente que ela - desenvolvimento potencial. Ou seja, para o teórico, é neste espaço entre o "real" e o "potencial", tendo em vista a relevância da interação e da inserção dos indivíduos em práticas sociais, que o desenvolvimento e as transformações acontecem.

No entanto, o conceito de ZDP vem passando por algumas expansões desde a sua formulação por Vygotsky. Magalhães (2012), com base em Vygotsky, destaca que o conceito de ZDP pode ser compreendido como um movimento de colaboração e contradição, mediado pela linguagem, constituindo relações de compreensão e ressignificação de sentidos e de produção compartilhada de significados. Apoiando-se em Newman e Holzman ([1993] 2002), a pesquisadora explica que a ZDP não representa um "lugar" ou um "instrumento", mas uma abstração, um "espaço de vida". Isso significa, segundo a autora, que as ações dos sujeitos, histórico e culturalmente situadas, são inevitavelmente motivadas pelas ações dos outros e produzidas a partir dessas ações, o que evidencia o caráter essencialmente dialógico e colaborativo-crítico desse movimento.

Holzman (2010), ao encontro dessa concepção, afirma que a criação de ZDP é um construto fundamental para a instauração do novo e para o entendimento da criatividade, vista como atividade necessariamente social e coletiva, superando a perspectiva do senso comum que vê o ato criativo como fruto da individualidade do sujeito.

É justamente essa possibilidade transformativa propiciada pela/na criação de ZDP que interessa - em especial- a este artigo. Isso porque entendemos que a alfabetização científica, desde a Educação Infantil, poderá colocar a criança, no movimento vivo e criativo da ZDP, em contato com o "novo", impulsionando a criança para além do que 
se podia fazer/compreender até o momento, o que pode favorecer a garantia de seus direitos de aprendizagem e da sua inserção cidadã, tal como preconizado pela BNCC.

A criação de possibilidades da ZDP, no âmbito da Educação Infantil, poderia favorecer não apenas a aprendizagem de conteúdos específicos, mas principalmente a compreensão de novas formas de ser e agir no mundo, criando espaços, na escola, de questionamento e descobertas. A iniciação ao universo científico pode representar, na vivência concreta da criança, um espaço lúdico, capaz de articular as relações entre o cotidiano infantil, o acervo cultural acumulado pela humanidade e a instauração do "novo", por meio da ampliação de sentidos e da (re)formulação de significados propiciados pela/na ZDP.

\section{METODOLOGIA}

Nesta seção, descreveremos os participantes, bem como detalharemos os procedimentos de produção e análise de dados da pesquisa aqui relatada.

\subsection{Participantes da pesquisa}

Nosso objetivo neste trabalho foi o de estudar a alfabetização científica no contexto da Educação Infantil, na intenção de verificar os impactos que uma mostra científica pode trazer para a alfabetização científica de estudantes nessa faixa etária.

O corpus da pesquisa foi obtido a partir da vídeo-gravação de entrevistas que realizamos com um total de 47 crianças na faixa etária compreendida entre 4 e 5 anos, antes e após terem visitado a mostra científica que preparamos.

Os sujeitos da pesquisa se constituíram de alunos da Educação Infantil de três escolas diferentes de um município do interior do Estado de São Paulo - Região do Vale do Paraíba.

A mostra de ciências que apresentamos contou com vinte e cinco experimentos demonstrativos contemplando temas como ótica, termodinâmica, ondulatória (som), eletricidade, magnetismo e eletromagnetismo. A mostra foi levada até a escola e montada no pátio para que as crianças pudessem interagir livremente com $o$ experimento. 


\subsection{Procedimentos de produção de dados}

Primeiramente, antes da realização da mostra científica, foi perguntado para as três turmas de alunos, cuja faixa etária estava compreendida entre 4 e 5 anos, no contexto de uma roda de conversa, se alguém sabia o que significava as seguintes palavras:

- Eletricidade;

- Calor;

- Dilatação;

- Contração;

- Reflexão e refração da luz;

Após a roda de conversa as crianças eram convidadas a participarem da mostra científica. Para cada experimento montado havia um monitor (um aluno do curso de licenciatura em Física). Esses monitores foram orientados para seguirem o seguinte roteiro de interação com as crianças:

- Apresentação e estabelecimento de vínculo: Apresentar-se para as crianças, falando seu nome, perguntando o nome delas, de forma a estabelecer um vínculo entre monitor e crianças;

- Definição de situação e contextualização: Falar do experimento de forma a mostrar como ele funciona;

- Manipulação: Incentivar a interação dos alunos com o experimento, deixando que eles os manipulassem livremente;

- Tomar consciência do que fizeram: Fazer perguntas as crianças buscando fazê-las descrever o que fizeram para que o experimento funcionasse;

- Estabelecer relações de causa e de efeito: Perguntar para as crianças o porquê achavam que sua ação desencadeou o efeito observado. 
Depois da mostra, os alunos passaram por uma entrevista. Um monitor entrou na sala, realizou uma nova roda de conversa e pediu para que as crianças falassem sobre o que sabiam sobre as seguintes palavras:

- Eletricidade;

- Calor;

- Dilatação;

- Contração;

- Reflexão e refração da luz;

A ideia era saber se as crianças conseguiriam relacionar essas palavras com os experimentos que realizaram na mostra.

Todas as etapas da pesquisa foram gravadas em vídeos e depois devidamente transcritas para posterior análise.

\subsection{Procedimentos de análise de dados}

Para a análise dos dados de nossa pesquisa, que se constitui das falas das crianças antes e depois da realização da mostra científica, utilizamos constructos da Teoria Sociocultural de Vygotsky, admitindo, portanto, a linguagem como determinante para o desenvolvimento do pensamento e, consequentemente, da cognição.

Como destaca Monteiro (2002), as pesquisas em Ensino de Ciências, desde a década de 90, têm evoluído, metodologicamente, de abordagens psicológicas, cognitivas, para outra de natureza sociológica, considerando a premissa de concepções epistemológicas modernas que entendem a Ciência como uma construção humana e, portanto, resultado de práticas culturais características de uma comunidade, a científica.

Assim, partimos do pressuposto que o ato de ensinar Ciência está relacionado com práticas de inserção sociocultural, na qual professores criam possibilidades de inserção sócio-histórico-cultural a seus alunos, introduzindo-os no mundo científico por meio de vivências. 
Em nossa pesquisa, analisamos as falas dos estudantes da Educação Infantil antes e depois da mostra científica, a partir dos constructos vygotskianos relativos ao processo de desenvolvimento do pensamento, ZDP e a partir dos processos de interação social.

\section{ANÁLISE E DISCUSSÃO DOS DADOS}

Os dados que obtivemos são mostrados nas tabelas a seguir. Os números mostrados entre parênteses indicam quantas vezes a palavra foi citada.

\section{a) Eletricidade}

É possível notar um aumento considerável de palavras e no número de citações das palavras citadas pelas crianças após a realização da mostra. Enquanto antes da mostra as crianças relacionaram apenas duas palavras ao termo eletricidade, após a interação delas com os experimentos, o número de palavras associadas aumenta para 9. Nesse aspecto evidencia-se que as interações sociais desencadeadas pelas atividades experimentais de demonstração da mostra propiciaram situações nas quais as crianças puderam ampliar o vocabulário utilizado em conexão com o termo eletricidade.

Tabela 1 - Palavras que as crianças associaram à eletricidade antes e depois da realização da mostra.

\begin{tabular}{cc}
\hline Antes da mostra & Depois da Mostra \\
\hline Choque (15) & Choque (54) \\
Tomada (37) & Luz (12) \\
& Televisão (13) \\
& Geladeira (15) \\
& Fio (22) \\
& Raio (17) \\
& Trovão (12) \\
& Chuva (10)
\end{tabular}

Fonte: Autoria própria. 
Quando avaliamos algumas frases elaboradas pelas crianças, identificando o contexto no qual as palavras destacadas surgem, temos:

Quadro 1- Frases construídas pelas crianças acerca da palavra eletricidade.

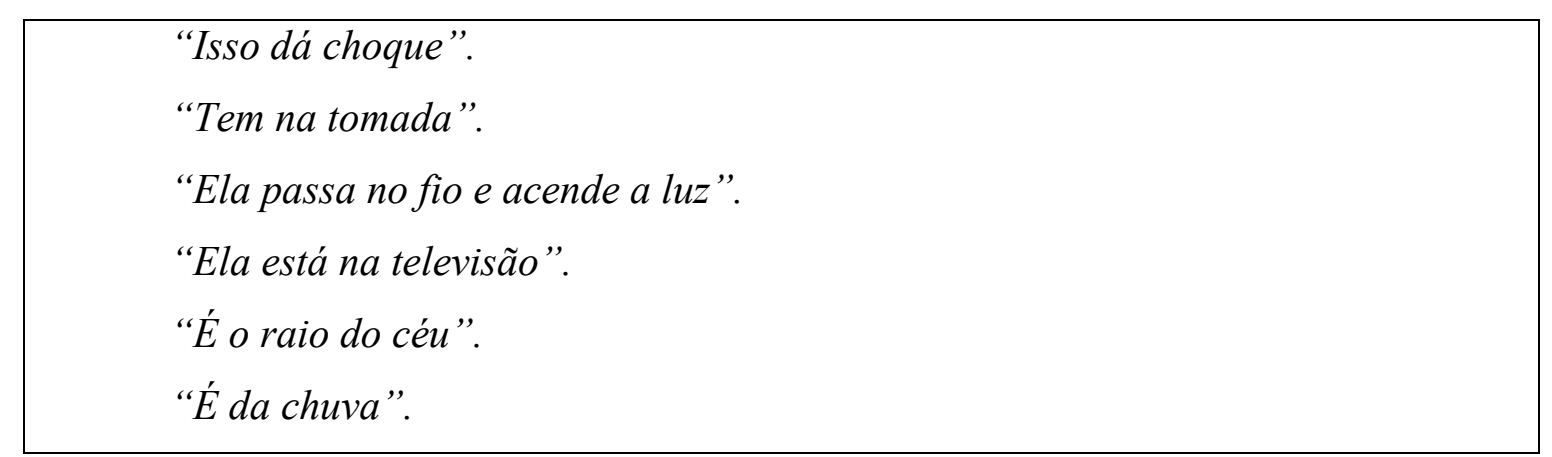

Fonte: Autoria própria.

É possível notar que nas frases as crianças identificam alguns fenômenos e situações que envolvem a eletricidade, como relacioná-la ao choque, à luz, ao funcionamento da televisão. É claro que ainda não conseguem estabelecer relação de causa e efeito, ou seja, diferenciando situações em que ocorre o choque e outra em que se acende uma lâmpada, por exemplo.

\section{b) Calor}

Em relação à palavra calor, após a realização da mostra, há um aumento de termos e citações de palavras relacionadas. Antes da mostra há 4 palavras relacionadas ao calor, enquanto que após a realização da mostra as crianças associam 9 palavras a esse termo. Nota-se que, novamente, a interação social propicia um aumento significativo do vocabulário das crianças envolvidas.

Tabela 2 - Palavras que as crianças associaram ao calor antes e depois da realização da mostra.

\section{Antes da mostra \\ Depois da Mostra}

Quente (8)

Fogo (34)

Sol (38)

Suor (9)
Quente (18)

Febre (9)

Sol (45)

Fogo (54) 
Temperatura (2)

Esquentar (22)

Fogão (26)

Comida (12)

Frio (6)

Fonte: Autoria própria.

Quando avaliamos as frases em que essas palavras surgem temos:

Quadro 2 - Frases construídas pelas crianças acerca da palavra calor.

"O calor deixa quente as coisas".

“Quando faz sol faz calor”.

"O fogo faz a gente sentir calor".

"O calor esquenta as coisas”.

"O fogão tem bastante calor".

"Calor esquenta a comida".

"O calor esquenta o frio".

"O calor esquenta a temperatura".

Fonte: Autoria própria.

As crianças não definem calor cientificamente, ou seja, a mostra não propicia esse nível de aprendizado. Contudo, é possível notar que elas não só relacionam palavras ao termo calor, mas conseguem identificar aspectos próprios do fenômeno, como por exemplo relacionar calor e a sensação de quente e relacionar a existência de calor a partir do sol e do fogo.

\section{c) Reflexão da luz}

Para o fenômeno da reflexão da luz não houve citações antes da mostra. Depois de sua realização apenas uma palavra foi relacionada e, assim mesmo, apenas 7 vezes.

Tabela 3 - Palavras que as crianças associaram à reflexão da luz antes e depois da realização da mostra. 
Fonte: Autoria própria.

Em relação às frases construídas pelas crianças temos:

Quadro 3- Frases construídas pelas crianças acerca da palavra reflexão da luz.

"É o espelho".

"É quando a gente vê o espelho".

"Tem no espelho”.

Fonte: Autoria própria.

Acreditamos que o fenômeno luminoso tenha sido por demais abstrato para as crianças e, por isso, a única coisa que conseguiram associar após a experiência tenha sido o espelho, artefato comum ao cotidiano delas.

\section{d) Refração da luz}

Nesse caso, em relação ao fenômeno da refração da luz, as crianças não conseguem estabelecer relação com nenhuma palavra nem antes e nem depois da mostra.

Tabela 4 - Palavras que as crianças associaram à refração da luz antes e depois da realização da mostra.

\section{Antes da mostra}

0

\section{Depois da Mostra}

0

Fonte: Autoria própria.

Nota-se que o fenômeno não faz parte do cotidiano das crianças e que o experimento realizado não conseguiu propiciar qualquer relação concreta com o dia-adia delas.

Este resultado, portanto, chama a atenção para o fato de que cada experimento deve ser cuidadosamente pensando para, de fato, envolver as crianças de forma a oferecer-lhes referências palpáveis. Destacam, também, a importância da realização de mostras científicas para crianças da Educação Infantil, tendo em vista que podem 
promover uma ampliação no repertório cultural dos estudantes facilitando futuras aprendizagens.

Segundo Vygotski (2001) a aprendizagem se estabelece a partir de um processo de interação social que ocorre, primeiramente, em um nível interpsicológico, a partir das interações sociais vivenciadas entre sujeitos, ou seja, é por meio da inserção na cultura que se possibilita a aprendizagem e o desenvolvimento. Em um segundo momento, a aprendizagem se consolida em termos intrapsicológicos a partir da interiorização dos significados que atribui a tudo que foi estabelecido nas interações sociais ocorridas.

Neste aspecto, a linguagem tem papel fundamental, já que ela é o meio a partir do qual se estabelecem as interações sociais. Em nosso trabalho, a palavra, recurso fundamental de linguagem de comunicação utilizado para se discutir os fenômenos com as crianças, foi utilizada por meio de interações desencadeadas pelo experimento utilizado.

$\mathrm{O}$ experimento se constituiu no principal artefato cultural que permitiu as discussões se estabelecerem. Quando antes da amostra uma palavra foi apresentada às crianças, as interações sociais possíveis de serem estabelecidas entre elas e os monitores se ocorreram em torno do repertório cultural das crianças. Toda ou qualquer palavra, necessária à definição de um fenômeno, que fosse utilizada por monitores, que não estivesse relacionado ao universo cultural delas não teria qualquer significado no momento da interiorização intrapsicológica.

Nesse caso, a realização do experimento permitiu que as crianças estabelecessem uma referência a partir do qual palavras e termos pudessem ter significados sóciohistoricamente definidos e negociados.

Além disso, podemos admitir que o uso do experimento, ao desencadear interações sociais ricas, ampliou o repertório cultural dos estudantes, criando possibilidades para a construção de conceitos mais complexos em outras interações sociais que venham a se realizar futuramente.

Do ponto de vista da teoria vygostkyana, isso pode ser também compreendido a partir do conceito de ZDP. Para Vygotsy (2001), práticas de ensino desenvolvidas na ZDP permitem avanços no desenvolvimento cognitivo do aprendiz, tornando-o capaz de 
aprendizagens mais complexas. Como argumenta Magalhães (2012), as ações dos sujeitos, histórico e culturalmente situadas, são inevitavelmente motivadas pelas ações dos outros e produzidas a partir dessas ações, o que evidencia o caráter essencialmente dialógico e colaborativo do espaço de vida criada na/pela ZDP.

$\mathrm{Na}$ esteira dessas definições, é possível perceber que, no contato com os experimentos da mostra e por meio das interações com os colegas e monitores, os sujeitos dessa pesquisa se deslocam da vivência cotidiana no movimento em direção ao "novo", o que se desvela, nitidamente, na ampliação de sentidos atribuídos pelas crianças nas entrevistas após a vivência dos experimentos.

Assim, mesmo que crianças da Educação Infantil não compreendam determinado conceito, em níveis mais aprofundados de conhecimento, o movimento de iniciação à ciência será de grande valia para que os estudantes, em um contexto de educação formal, tenham condições de se desenvolverem, ampliando seus sentidos sobre artefatos científicos e compartilhando novos significados.

\section{CONSIDERAÇÕES FINAIS}

Neste trabalho, constatamos que as interações sociais desencadeadas a partir de um experimento de demonstração experimental realizada no contexto de um mostra de ciências pode ampliar a capacidade do aluno em interiorizar significados importantes, que, mais tarde, servirão de base para compreensão de conceitos e ideias mais complexas e com grau maior de abstração.

Assim, a realização de mostras de ciências, em especial na Educação Infantil, pode propiciar um maior embasamento para que aprendizagens mais complexas a serem construídas nas etapas educacionais posteriores se deem de maneira mais significativa.

É claro que os alunos não conseguiram se apropriar dos conceitos relacionados à mostra e tampouco é licíto afirmar que a vivência da mostra engendraria, necessariamente, a alfabetização científica dos participantres. Ainda assim, , acreditamos que a ampliação do repertório cultural dos estudantes, caracterizado pela ampliação das relações que foram capazes de estabelecer com as palavras a que remetem os conceitos, oferecem meios para que, em etapas posteriores de ensino, em 
que se exige um pensamento mais abstrato dos estudantes, tenham subsídios para que o processo de ensino-aprendizagem ocorra de maneira mais fácil e, sem dúvida, possam ser criadas possibilidades concretas para a alfabetização cientítica dos alunos, tal como discutimos ao longo deste artigo.

Entretanto, nosso trabalho investigativo identificou que não é qualquer mostra que traz impacto significativo para as crianças. É fundamental que a mostra seja preparada com experimentos de demonstração cujo aparato experimental seja concebido de maneira a relacionar o fenômeno a ser estudado com elementos do cotidiano da realidade do estudante, aproximando o movimento escolar da realidade, de fato, vivida por alunos e professores.

\section{REFERÊNCIAS}

AGUILAR, T. Alfabetización científica y educación para la ciudadanía. Madrid: Narcea, 1999.

ALMEIDA, E. R. S. TERÁN A. F. A. Alfabetização científica na educação infantil: possibilidades de integração Conferencia da Associação. Latinoamericana de Investigação em Educação em Ciências. Manaus-AM, Brasil, 2013.

BAKHTIN, M. 1979. Estética da criação verbal. 6.ed. São Paulo: Martins Fontes, 2011.

BERSCH B. R.; SALVATORI,Tomás Sa , MARCH, M. I. , SALVATORI, R. U., STROHSCHOEN, A. A. G. Viagem ao mundo invisível: busca pela alfabetização científica na educação infantil e ensino médio. Caderno pedagógico, Lajeado, v. 10, n. 1, p. 109-117, 2013

BORGES, C. S., RAMOS, A. S. AMORIM, K. P. A importância do ensino de Ciências de forma prática e lúdica na Educação Infantil. IV FIPID - Fórum Internacional de Pedagogia- Santa Maria- RS, 2014.

BRANDI, A. T. E.; GURGEL, C. M. A. A Alfabetização científica e o processo de ler e escrever em séries iniciais: Emergências de um estudo de investigação-ação. Ciência \& Educação, v.8, nº1, p.113 - 125, 2002.

BRASIL. Base Nacional Comum Curricular (BNCC). Educação é a base. Brasília, MEC/CONSED/UNDIME, 2017. Disponível em: http://basenacionalcomum.mec.gov.br/images/BNCC_publicacao.pdf. Acesso em: 02 jun. 2019. 
BRITO L. O.; FIREMAN E. C. Uma estratégia pedagógica para promoção da alfabetização científica nos primeiros anos do ensino fundamental. Universidade Federal de Alagoas Programa de Pós-graduação em Ensino de Ciências e Matemática, Alagoas; 2014.

CHASSOT, A. Educação conSciência. Santa cruz do sul: Edunisc. ( 2. Ed.2007 e 2. reimpressão 2014.

FREIRE, Paulo. Educação e Mudança. Rio de Janeiro: Paz e Terra, 1979.

GUERRA, S. A quarta onda globalizante e os desafios para o direito internacional. Revista da Faculdade de Direito de Campos, Campos de Goytacazes, v.4-5, n. 4-5, 2004.

HOLZMAN, L. Without Creating ZPDs There is No Creativity. In: CONNERY, C.;

JOHN-STEINER, V.; MARAJANOVIC-SHANE, A. (Eds.). Vygotsky and Creativity. Nova York: Peter Lang Publishers, 2010. p.27-39.

LIBERALI, F.C. Cadeia criativa: uma possibilidade para a formação crítica na perspectiva da Teoria da Atividade Sócio-Histórico-Cultural. In: MAGALHÃES,

M.C.C.; FIDALGO, S.S. Questões de método e de linguagem na formação docente. Campinas: Mercado de letras, 2011. p. 41-64.

LORENZETTI, L.; DELIZOICOV, D. Alfabetização científica no contexto das séries inicias. Ensaio - Pesquisa em Educação em Ciências, v. 3, n. 1, jun. 2001.

MAGALHÃES, M.C.C. Vygotsky e a pesquisa de intervenção em contexto escolar: a pesquisa crítica de colaboração - PCCOL. In: LIBERALI, F.C.; MATEUS, E.;

DAMIANOVIC, M.C. A Teoria da Atividade Sócio-Histórico-Cultural e a escola: recriando realidades sociais. Campinas: Pontes Editores, 2012. p. 13-26.

MONTEIRO, M.A.A. Um estudo da autonomia docente no contexto do ensino de ciências nas séries iniciais do ensino fundamental. 2006. 305 f. Tese (Doutorado em Educação para a Ciência). Faculdade de Ciências, UNESP, Bauru, 2006.

MONTEIRO, M.A.A. Interações dialógicas em aulas de ciências nas séries iniciais: um estudo do discurso do professor e as argumentações construídas pelos alunos. Bauru/SP, 2002. 204 p. Dissertação (Mestrado em Educação para a Ciência, Área de Concentração: Ensino de Ciências), UNESP, Campus de Bauru, 2002.

NEWMAN, F.; HOLZMAN, L. Lev Vygotksy: cientista revolucionário. São Paulo: Edições Loyola, 2002. 
NININ, M.O.G. Da pergunta como ato monológico avaliativo à pergunta como espaço para expansão dialógica: uma investigação à luz da linguística aplicada sobre modos de perguntar. São Carlos: Pedro e João Editores, 2013.

OLIVEIRA, E. Outubro Rosa e Ensino de Ciências na Educação do Campo. Revista Insignare Scientia - RIS, v. 3, n. 4, p. 460-476, 20 nov. 2020.

OLIVEIRA, M. C.; ASSIS, A.; TRAVAIN, S. Doenças Negligenciadas: proposta de uma sequência didática pautada no enfoque CTS. Revista Insignare Scientia - RIS, v. 2, n. 4, p. 332-348, 19 dez. 2019.

PUIGCERVER, M.; SANS, M. C. Vacas locas, enseñanza: aprendizaje y alfabetización científica. Alambique - Didáctica de las ciências experimentales, n. 32, 2002.

SACRISTÁN, J. G. O significado e a função da globalização na sociedade e na cultura globalizada. In: GARCIA, L.R.; MOREIRA, A.F.B. (orgs). Currículo na contemporaneidade: incertezas e desafios. São Paulo: Cortez, 2003.

SASSERON, L. H.\& CARVALHO, A. M. P. Almejando a Alfabetização Científica no Ensino Fundamental: a proposição e a procura de indicadores do processo. Investigações em Ensino de Ciências. Porto Alegre, v.13, n. 3, 333-352, 2008.

SAUSSURE, F. Curso de Linguística Geral. Org. por Charles Bally e Albert Sechehaye com a colaboração de Albert Riediliger. 5. ed. São Paulo: Cultrix, 1971.

VYGOTSKY, L.S. Linguagem, Desenvolvimento e Aprendizagem. São Paulo, Ícone, 1988.

VIGOTSKI, L. S. A formação social da mente. São Paulo: Martins Fontes, 1991.

VIGOTSKI, L. S. Pensamento e linguagem. São Paulo: Martins Fontes, 1993.

VIGOTSKI, L. S. A construção do pensamento e da linguagem. São Paulo: Martins Fontes, 2001. 